\title{
A diagnostic assessment of the health system's response to female genital mutilation/cutting management and prevention in Kenya: A case study of West Pokot County
}

Samuel Kimani

Population Council

Follow this and additional works at: https://knowledgecommons.popcouncil.org/departments_sbsr-rh

Part of the Demography, Population, and Ecology Commons, Family, Life Course, and Society Commons, Gender and Sexuality Commons, International Public Health Commons, and the Medicine and Health Commons How does access to this work benefit you? Let us know!

\section{Recommended Citation}

Kimani, Samuel. 2020. "A diagnostic assessment of the health system's response to female genital mutilation/cutting management and prevention in Kenya: A case study of West Pokot County," Evidence to End FGM/C: Research to Help Girls and Women Thrive. New York: Population Council. 


\section{A DIAGNOSTIC ASSESSMENT OF THE HEALTH SYSTEM'S RESPONSE TO FEMALE GENITAL MUTILATION/CUTTING MANAGEMENT AND PREVENTION IN KENYA: A CASE STUDY OF WEST POKOT COUNTY}

\section{BACKGROUND}

Female genital mutilation (FGM/C), a pervasive cultural practice in some contexts, is associated with negative impacts on women's and girls' health and rights. The health sector is well positioned to respond to the prevention of $\mathrm{FGM} / \mathrm{C}$ and the management of its complications because of its primary role in disease prevention, health promotion and curative services. In Kenya, the health sector's role is anchored in national and county legal and policy instruments and guidelines that are adopted or customised from global or regional frameworks as well as skills support tools approved by $\mathrm{WHO}$.

Despite the existence of instruments, guidelines and tools that should direct a robust health system's response to $\mathrm{FGM} / \mathrm{C}$, the practice persists-with emerging shifts, notably medicalisation, posing substantial challenges. Additionally, evidence on the implementation of relevant FGM/C-related legal or policy frameworks in the health sector is scarce.

This brief highlights findings from a recent study ${ }^{1}$ of the health system in West Pokot County in Kenya. The aims of the study were to:

- examine how the healthcare sector supports the prevention of $\mathrm{FGM} / \mathrm{C}$;

- determine the health sector's role in the management of $\mathrm{FGM} / \mathrm{C}$ related complications and the quality of care offered to clients; and

- identify possible solutions for strengthening the healthcare system's capacity to manage and prevent FGM/C.

West Pokot County was selected because of the high prevalence of $\mathrm{FGM} / \mathrm{C}$, particularly infibulation, which is associated with an increased risk of health complications. ${ }^{2}$

\section{METHODS}

We conducted a mixed-method study involving qualitative and quantitative data collection at the national and county level. A summary of the datacollection activities is presented in Figure 1.

\section{RECOMMENDATIONS}

- Sensitise healthcare providers about laws and policies relevant to health sector-led FGM/C-related prevention and management.

- Develop support tools for healthcare providers on FGM/C-related prevention and management interventions.

- Enhance healthcare providers' capacities to manage women and girls with FGM/C-related complications, including sexual and psychological complications.

- Strengthen the referral system for FGM/C-related complications through identification and establishment of a database of specialists and health facilities offering FGM/C interventions.

- Ensure that FGM/C data are anchored in the health management information system and that appropriate tools for the collection and documentation of FGM/C data are availed

- Advocate for gender responsive budgeting to hold the health sector accountable for investing in the prevention and management of FGM/C 
Figure 1. Data-collection activities

- Key informant interviews $(n=34)$ with policy actors at national and county levels

- Four focus group discussions with health service providers (doctors, nurse-midwives, clinical officers)

- In-depth interviews $(n=23)$ with health service providers

- Health facility assessments $(n=30)$

- Observations of client-provider interactions $(n=61)$

- $\quad$ Client exit interviews $(n=360)$

- $\quad$ Service data abstraction (10 facilities)

\section{KEY FINDINGS}

What is the legal and policy framework that anchors the health system's response? Notable laws that address FGM/C prevention and management include the Children's Act of 2001, Prohibition of FGM Act of 2011, Protection Against Domestic Violence Act of 2015, and the Penal Code Cap. 63. Similarly, relevant policies guiding the health sector to address FGM/C include the Adolescent Sexual and Reproductive Health Policy of 2015, and the National School Health Policy of 2009.

Few health-service providers were, however, aware of these instruments at the operational level. This in turn impacts implementation and service delivery to women and girls with FGM/C.

What is the health system's capacity to deliver preventive and curative FGM/C services? Although health facilities in West Pokot had the requisite infrastructure and human capacity to implement preventive interventions for $\mathrm{FGM} / \mathrm{C}$, few health sector-led FGM/C-related interventions were implemented. The primary reason for the limited number of $\mathrm{FGM} / \mathrm{C}$ preventive interventions was the lack of resources, namely funds; guidelines; protocols; and information, education, and communication (IEC) materials. Furthermore, lack of skills and expertise in implementing interventions for women with FGM/C was evidenced by a high number of referrals and erroneous indications for caesarean section and double episiotomies instead of the standard de-infibulation for women with birth complications.

\section{What FGM/C-related health services are provided?}

- Women and girls sought services for immediate, obstetric, gynaecologic, sexual, and psychological complications of FGM/C.

- Providers noted that it was challenging to effectively manage these complications. For example, managing excessive bleeding was difficult because facilities lacked blood banks, prompting referral. In some instances, the providers lacked skills to perform de-infibulation on women with birth complications and instead performed a double episiotomy or caesarean section or referred to the next-level health facility.

- There was limited evidence on how FGM/Crelated sexual and psychological complications were managed.
- Results of the observations of client-provider interaction showed that few healthcare providers discussed FGM/C with their clients (Figure 2).

- $\quad$ Although referrals for women and girls with obstetric, gynaecologic, and immediate complications were reported, it was unclear how the referral system worked.

Figure 1. Percentage of health providers who discussed FGM/C with patients (source: client-provider interactions, $n=61$ )

\begin{tabular}{|c|c|}
\hline $\begin{array}{c}\text { Explained how FGM/C might } \\
\text { have undermined health } \\
\text { physically and mentally } \\
\begin{array}{c}\text { Asked about possible effects of } \\
\text { FGM/C }\end{array}\end{array}$ \\
\hline $\begin{array}{c}\text { Asked about the severity of cut } \\
\text { Asked whether client has been } \\
\text { cut before }\end{array}$ & 8 \\
\hline
\end{tabular}

\section{What FGM/C-related data are collected?}

Health workers rarely documented FGM/C cases or complications because of the lack of data-collection tools at facilities

"We don't capture the data on how many girls or women came into the health facility because of FGM or related deaths, what caused the death? I don't know whether if you go to those facilities to look for such kind of data you will get it."Representative of an NGO dealing with legal issues for women, Nairobi

\section{CONCLUSION}

Although Kenya has robust legal and policy frameworks that should direct the health sector's response to $\mathrm{FGM} / \mathrm{C}$, implementation of actionable interventions is inconsistent or lacking. This is evidenced by minimal FGM/C prevention interventions and explicit challenges in the management of FGM/C complications. These findings underscore the need for the health sector to translate relevant legal or policy frameworks into tools that can support interventions aimed at preventing $\mathrm{FGM} / \mathrm{C}$, and improve the quality of care received by women and girls living with $\mathrm{FGM} / \mathrm{C}$, as well as to enhance the monitoring and evaluation of the health system's responses.

\section{REFERENCES}

1. Kimani, S. and C. Okondo. 2020. A Diagnostic Assessment of Health System's Response to Female Genital Mutilation/Cutting Management and Prevention in Kenya. Evidence to End FGM/C: Research to Help Girls and Women Thrive. New York: Population Council.

2. United Nations Children's Fund (UNICEF). 2017. Baseline Study Report: Female Genital Mutilation/ Cutting and Child Marriage among the Rendille, Maasai, Pokot, Samburu and Somali Communities in Kenya. Nairobi: UNICEF. 